\title{
“POR UN LUGAR EN LA CIUDAD”. EL USO DE IMÁGENES EN UN CONFLICTO SOCIOAMBIENTAL
}

\author{
Agustina Girado
}

\section{Introducción}

El presente artículo exhibe algunas reflexiones surgidas de la investigación que llevé adelante entre los años 2008-2011 para la obtención de mi tesis de Licenciatura en Antropología Social ${ }^{2}$. La misma aborda un conflicto socioambiental existente en la ciudad de Tandil, provincia de Buenos Aires, en donde distintos actores colectivos se enfrentan por la apropiación de un recurso natural sobre la base de disimiles valoraciones y prácticas. En este sentido, la dimensión ambiental y, más específicamente, el uso, gestión y ocupación del sistema serrano de Tandilia $^{3}$ se transforma en un elemento de disputa, argumentación, legitimación y negociación entre diferentes grupos de la sociedad y sectores del Estado.

Para este artículo me concentrare en la utilización de la imagen fotográfica en el trabajo etnográfico como herramienta para la construcción de conocimientos respecto al campo semántico de disputa que se genera en la ciudad media ${ }^{4}$ de Tandil en torno a la explotación/preservación del recurso natural sierras, elemento significativo de la dinámica cultural urbana (Silva, 2010) a partir del cual se vislumbra y pueden analizarse los modos de vivir la ciudad, los sentidos y prácticas que los diversos actores sociales construyen y manifiestan cotidianamente. Asimismo, el énfasis estará colocado en la cuestión de lo público y lo privado como eje vertebrador de las decisiones éticas/metodológicas en la investigación social, en donde el contexto de registro y las relaciones concretas que se

\footnotetext{
${ }^{1}$ Universidad Nacional del Centro de la Provincia de Buenos Aires, Argentina.

${ }^{2}$ Realizada en la Facultad de Ciencias Sociales de Olavarría perteneciente a la Universidad Nacional del Centro de la Provincia de Buenos Aires.

${ }^{3}$ Macizo de piedra que se formó geológicamente hace 2.500 millones de años. El sistema de Tandilia consiste en un conjunto de pequeñas "islas" rocosas que nacen en la pampa húmeda y se extienden en sentido NO-SE, desde Olavarría hacia la Costa Atlántica. Este recurso se encuentra cargado de sentidos culturales puesto que los ciudadanos de Tandil le otorgan una relevancia significativa en sus vidas y en el desarrollo de la ciudad.

4 La categoría de "ciudad de rango medio" o "ciudad intermedia" generalmente se construye a partir de indicadores estructurales y de funcionalidad; el rango poblacional que se considera es entre 50000 a 500000 habitantes. Sin embargo, existen otras aproximaciones teóricas que intentan determinar la especificidad de los centros urbanos de rango intermedio a partir de la inclusión de las dinámicas simbólicas en el análisis, véase Gravano (2005) y Boggi (2008).
} 
establecen con los actores en disputa posibilitan redefinir las estrategias metodológicas y objetivos de investigación.

En el marco del conflicto de intereses y perspectivas en torno al uso, gestión y ocupación del sistema serrano, el gobierno Municipal implementó desde la década de 1970 diversas medidas legales que posibilitaron cambios en la gestión del recurso sierras a los fines de lograr "solucionar" las problemáticas socioambientales de la explotación minera y de las construcciones sobre las sierras. Sin embargo, estos cambios no obedecen únicamente al pedido histórico de la ciudadanía por la preservación del recurso natural, sino que se asocian con el proyecto de ciudad que contempla e imagina el Municipio.

En este sentido, se analizaran las repercusiones sociopolíticas que generó la sanción de la Ley de Paisaje Protegido No 14.126 y su decreto de reglamentación. La medida legal estableció la prohibición de la actividad minera dentro de la zona denominada la poligonal (intersección de las actuales Rutas Nacional No 226 y Provinciales $N^{o} 74$ y No 30). Este hecho permitió desvelar los conflictos que se producen como consecuencia de la separación entre los procesos de elaboración de políticas y sus aplicaciones (Noé Echeverría, 1998). En la reglamentación de la ley no existió una activa participación social de aquellos sectores involucrados en la problemática minera, sino que sólo trabajaron en su elaboración funcionarios municipales y provinciales, cientistas locales e, indirectamente, agrupaciones ambientalistas de la localidad. En consecuencia, el Plan de Manejo Ambiental que contempla la reglamentación de la ley hizo mella en aquellos actores secundarios que no estuvieron directamente implicados: empresarios canteristas, trabajadores mineros y transportistas, dando lugar a un recrudecimiento desestabilizador y mediático de la problemática socioambiental en el ámbito público (Girado, 2012).

Esta intensificación del conflicto socioambiental permite ilustrar el carácter complejo y dinámico de los conflictos y, al mismo tiempo, dar cuenta de la persistencia de una lógica de acción por parte de los actores sociales ya que las empresas mineras se posicionaron fuertemente en la opinión pública respecto a la persistencia de la actividad extractiva tratando de evitar la pérdida de poder, gran parte de la ciudadanía resistió a sus exigencias y condiciones de funcionamiento, los funcionarios realizaron diferentes teatralizaciones suscribiendo a una concepción de la política como un drama o una puesta 
en escena (Balandier, 1994), y la ocupación del espacio público apareció en todo su dramatismo.

\section{Trabajo etnográfico y uso de fotografías}

En la investigación antropológica el enfoque etnográfico posibilita llevar a cabo un proceso de construcción de conocimiento respecto a diversas problemáticas a partir de documentar lo no documentado (Rockwell, 2009), lo implícito, lo oculto, lo no formalizado, y de acceder al universo socio-cultural de los actores sociales dando cuenta de sus representaciones y acciones, tratando de describirlas, interpretarlas, explicarlas y ponerlas en contexto. La etnografía no solamente designa a la forma de proceder en la investigación sino que también hace referencia al producto final que se obtiene de la misma sobre la base de la reflexividad (Guber, 1990; Hammersley y Atkinson, 1995), y de un peculiar modo de teorizar, de problematizar la realidad, de hacer preguntas y de atender a los procesos sociales en su discurrir y en su devenir (Grassi, 2004).

En la mayoría de las investigaciones en ciencias sociales, el trabajo en terreno se aborda a partir de técnicas cualitativas tradicionales de la etnografía, siendo la compleja técnica conceptual de la observación participante y el soporte material del cuaderno de notas los dos elementos clásicos del trabajo de campo a partir de los cuales se accede a la diversidad de experiencias, discursos, acciones y representaciones que manifiestan los actores en relación a un determinado problema empírico. Asimismo el investigador puede valerse de otras técnicas cualitativas y cuantitativas para la obtención y tratamiento de los datos, como por ejemplo los medios audiovisuales.

La interrelación entre los medios audiovisuales, específicamente la fotografía, y la Antropología se remonta a los inicios de ambas. La fotografía ha servido a la Antropología como un instrumento de recogida de datos, sin embargo después de la institucionalización de la subdisciplina de la Antropología Visual en la década del '60, también se constituyó en objeto de investigación y medio para la difusión de conocimientos (Edwards, 1992, 2009; Ardèvol, 1994,1998, 2006; Gazzotti, 2008; Lezama, 2001; Rocha y Eckert, 2000).

En un principio el interés antropológico por las fotografías se centraba en sus contenidos y significados, siendo entendida principalmente como representación. En este sentido, la fotografía permitía por un lado, conocer las distintas maneras de representación 
de los sujetos sociales estudiados y, por otro, reflexionar respecto a cómo se utilizaba la representación visual en la Antropología, lo que al mismo tiempo posibilitaba cuestionar el supuesto de que la fotografía científica proporcionaba información objetiva y neutral de la realidad investigada.

La creciente reflexión antropológica respecto a los medios audiovisuales posibilitó pensar a la fotografía no sólo como representación sino también como práctica y objeto material, siendo importantes sus contextos de creación y circulación. Este nuevo enfoque privilegió analíticamente "lo experiencial por encima de lo semiótico" (Edwards, 2009: 104), es decir, lo que las personas hacen con las fotos y no exclusivamente lo que aparecen haciendo en ellas. Así, las cambiantes significaciones de las fotografías se vinculan a sus contextos de producción y de uso en tanto objetos materiales y simbólicos.

Otro aspecto central en lo que respecta el uso de imágenes fotográficas en investigaciones antropológicas se vincula a los problemas éticos que se presentan en la práctica profesional y que conllevan a la redefinición del trabajo etnográfico, no solamente en relación a la construcción del objeto de estudio, sino también a la elección de las estrategias y metodologías que orientan la investigación. Dichas redefiniciones posibilitan indagar por un lado, sobre el sentido de las prácticas, es decir, preguntarse para qué y para quienes es el trabajo etnográfico, cuál es el mejor modo de realizarlo y qué repercusiones puede generar el mismo y, por otro lado, permite problematizar el tipo de relación que se establece con los actores sociales investigados.

De este modo, los contextos de registro ocupan un lugar central en la reflexión ética de la investigación social puesto que el carácter público y privado de los espacios utilizados y apropiados por los actores sociales determina si es necesario solicitar un consentimiento informado. Adolfo Estalella y Elisenda Ardèvol (2007) mencionan que si bien las guías éticas le otorgan un papel preponderante en la investigación al consentimiento informado, suelen proponer una excepción cuando la misma se realiza en espacios públicos como por ejemplo calles y plazas. Sin embargo, también mencionan que esa excepción posee dos correctivos:

(...) (i) la participación del investigador y (ii) el tipo de registro que se realiza. Si el investigador interactúa con la gente durante la investigación, aunque ésta se realice en una plaza pública, debe solicitar el consentimiento informado; y si el tipo de registro que se realiza es permanente, como grabaciones de audio o de video, debe al menos 
informarse a las personas de que están siendo grabadas (NESH, 2001). Esta regla de excepción es especialmente útil en el caso de investigaciones observacionales y de tipo documental, pero también para la etnógrafa en cuanto debe recurrir a la cultura material y a fuentes documentales para completar sus observaciones o para poder realizar su trabajo de campo cuando éste también transcurre en contextos públicos (...)

(Estalella y Ardèvol, 2007: 7)

La dimensión visual se torna crucial en el estudio de las distintas expresiones socioculturales, políticas, económicas y ambientales que producen y expresan los sujetos sociales. En este sentido, la imagen fotográfica debe reconocer los discursos y prácticas de los sujetos presentes en el espacio público, como así también los significados que se construyen más allá de ese espacio pero que se reproducen, debaten y tensionan allí mismo. De este modo, las fotografías refractan los múltiples sentidos e intereses en pugna y, al mismo tiempo, resultan una herramienta útil a partir de la cual el investigador y los actores sociales "construyen" la historia de un modo particular atendiendo a sus posicionamientos, conocimientos e intereses.

Quizás uno de los aspectos más debatidos en la disciplina antropológica es cómo la presencia de una cámara modifica y complejiza los discursos y prácticas de las personas, pero como sostiene Ardébol (1994) este debate también subyace cuando se trabaja con un lápiz, cuaderno de notas o grabador. Es cierto que la cámara modifica el comportamiento de los actores sociales y también el del propio investigador puesto que nunca será un instrumento neutral para las personas representadas ni para el proceso y el resultado de la investigación. Empero, la imagen fotográfica brinda otro recurso para explorar y analizar las disputas locales, los imaginarios urbanos, la opacidad y transparencia de los discursos, las estructuras de sentido y sistemas culturales que atraviesan a los actores sociales estudiados.

Si bien la utilización de medios audiovisuales en la investigación antropológica resulta un camino abierto, permeado de múltiples debates e inquietudes, las reflexiones suscitadas en torno a las imágenes fotográficas han posibilitado entenderlas no sólo como representaciones sino también como prácticas, siendo los contextos de producción y las relaciones con lo actores sociales elementos nodales para entender cómo creamos, tratamos y damos sentido a las imágenes en tanto productos sociohistóricos, "visiones del mundo". 


\section{Cambios en la gestión del recurso sierras: disputas en torno a la Ley de Paisaje Protegido}

La historia de la ciudad de Tandil se encuentra ligada al desarrollo de la explotación minera pre-industrial, similitud compartida con otras ciudades serranas de la región. En este sentido, la actividad de los picapedreros comenzó a fines del siglo XIX y se constituyó en una actividad relevante para la economía local. El auge de la explotación minera se basó en la calidad del material granítico extraído en la zona, en la presencia de población inmigrante que proveía mano de obra especializada en el oficio de la piedra y, fundamentalmente, a la cercanía relativa respecto de los centros demandantes (Girado, 2012).

Sin embargo, desde 1970 el crecimiento urbano hacia zonas serranas ocasionó que las canteras quedaran próximas a los límites del casco urbano, generando por un lado, los primeros enfrentamientos entre los canteristas y los vecinos más cercanos a las empresas mineras y, por otro, la visualización de las metodologías extractivistas y los impactos socioambientales de la actividad.

Asimismo, los cambios sociales, económicos y políticos acontecidos durante la década del '90 a nivel nacional impactaron en el desarrollo de la explotación minera local. Por una parte, la evolución y diversificación de la economía de Tandil implicó que la explotación de las canteras perdiera importancia relativa en cuanto a ingresos municipales. Por otra parte, los cambios en el tipo de producto y las nuevas tecnologías utilizadas provocaron la connivencia de poca y especializada mano de obra con explotación intensiva y depredadora del recurso sierras. En sintonía con estos cambios en la explotación minera se comenzó a ponderar la preservación del recurso natural sierras con fines turísticos, recreativos e inmobiliarios, alimentando la representación a nivel local y regional de Tandil como la "ciudad de las sierras",

De este modo, la lucha por la preservación de las sierras, lo cual atañe a las políticas de patrimonio y gestión social del territorio, ha generado un acalorado debate en la sociedad tandilense desde la década del '70 hasta la actualidad. Su inscripción en los discursos y prácticas de una gran diversidad de actores sociales y la fuerte presencia de la

\footnotetext{
${ }^{5}$ Para entender como el medio ambiente es apropiado y resignificado como elemento constitutivo de la producción simbólica de la vida urbana en la ciudad de Tandil véase Gravano (2005) y Silva (2010).
} 
problemática en los debates políticos, económicos y culturales permite interpretar su relevancia en la agenda pública.

En este contexto, las elecciones políticas del 2003 significaron la inclusión de la problemática de la explotación minera en las plataformas electorales; el candidato electo por la Unión Cívica Radical (UCR), Miguel Ángel Lunghi, instauró el lema “ni una explosión más”, generando en la población expectativas de cambios en la gestión y explotación del cordón serrano. En consonancia con este clima comunitario, en el año 2005 se aprobó un nuevo Plan de Desarrollo Territorial (PDT) el cual estableció un Plan de Manejo Especial de la Zona Protegida "Sierras de Tandil” para regular el uso, ocupación, subdivisión y equipamiento del suelo, al igual que determinar el sistema de gestión territorial. Sin embargo, las problemáticas de la explotación minera y las incipientes construcciones sobre el faldeo serrano continuaron siendo el foco de múltiples críticas.

En el marco de este conflicto por la explotación/preservación del sistema serrano, sectores de la oposición política elaboraron un proyecto de ley recogiendo parte de las históricas declamaciones de las agrupaciones ambientalistas ${ }^{6}$ y diversos sectores de la población local. Si bien el proyecto fue gestionado por un senador tandilense del Frente Para la Victoria (FPV), una vez ingresado al Senado Provincial en el año 2009 fue cooptado políticamente y enarbolado mediáticamente por el oficialismo radical. Finalmente, en el año 2010 la Cámara de Diputados aprobó la Ley de Paisaje Protegido No 14.126, después de dilatarse en reiteradas oportunidades el tratamiento del proyecto y de generar arduos debates entre los diferentes bloques políticos ${ }^{7}$.

A modo general, el proyecto presentado “(...) tiene por objeto conservar y preservar la integridad del paisaje geográfico, geomorfológico, turístico y urbanístico del área especificada en el artículo $1^{\circ}$ " (Artículo 2), la denominada poligonal. Para el cumplimiento del mencionado artículo, en el área especificada, no puede habilitarse la instalación de nuevas explotaciones mineras, y las canteras que allí se localizaban -El Centinela, Yarda (Montecristo), Petrominera (El Naranjo) y Carba (Cantera Albión)-

\footnotetext{
${ }^{6}$ Las agrupaciones ambientalistas exigen la declaración de las sierras como "Áreas Protegidas" puesto que la mencionada figura legal, a diferencia del "Paisaje Protegido", incluye a la totalidad del sistema serrano y posibilitaría un efectivo cese de las actividades mineras, de las construcciones sobre las sierras y de las forestaciones exóticas.

${ }^{7}$ Los aspectos más debatidos por los funcionarios fueron: el temor a que la medida legal fijara un precedente en la provincia de Buenos Aires respecto a la explotación minera y la posibilidad de que las empresas afectadas realizaran juicios millonarios contra el Estado.
} 
debían cesar su funcionamiento en un plazo no superior a 1 año. Sumado a ello, el Estado podía realizar una interrupción anticipada de la actividad de no ser presentados y aprobados los planes de reconversión.

De los 16 artículos de la ley, 7 son para garantizar los derechos de los trabajadores. Ante el cese de la actividad minera los mismos serían incorporados en el Estado municipal o provincial, siempre que la persona así lo dese, y gozarían de los mismos haberes que recibieron en la empresa (incluyendo antigüedad, carga familiar, categoría y las horas extras que le correspondían al momento de ser interrumpido su trabajo). Asimismo, el Estado municipal y provincial se harían cargo de sus indemnizaciones al momento del cese laboral “(...) en un todo de acuerdo con el régimen establecido por la Ley de Contrato de Trabajo $N^{\circ} 20.744$, artículo $245^{\circ}$ de la misma. " (Artículo 9)

En lo que respecta al decreto de reglamentación de la Ley $\mathrm{N}^{\mathrm{o}} 14.126$ que declaró Paisaje Protegido de Interés Provincial al área del Partido de Tandil denominada la poligonal, fue promulgado a fines del año 2010 y posibilitó establecer los lineamientos específicos para la formulación del Plan de Manejo Ambiental que permitirá la administración del Paisaje Protegido, así como el procedimiento para la reconversión de las explotaciones mineras y los mecanismos para regularizar la situación de los trabajadores pertenecientes a las canteras localizadas en la zona de la poligonal.

El Plan de Manejo Ambiental fue elaborado por el Organismos Provincial para el Desarrollo Sostenible (OPDS) conjuntamente con el Municipio de Tandil y con la participación de otras autoridades provinciales con competencias en el tema. El mismo debía ser presentado en el término máximo de 4 meses a partir de la entrada en vigencia del mencionado decreto, pero el plazo se extendió bajo el argumento de que el tiempo asignado resultaba insuficiente para elaborar un Plan de Manejo que permita una efectiva protección del sistema serrano.

Si bien la promulgación de la ley fue vivenciada por diversos sectores de la población local como un logro obtenido después de más de 20 años de lucha contra la explotación y degradación de las sierras, también genero una arena de disputas en relación a su sentido y a sus efectos (Gluckman, 2003) ${ }^{8}$.

\footnotetext{
${ }^{8}$ Max Gluckman (2003) se refiere a ciertos acontecimientos o eventos como "situaciones sociales", en tanto acontecimientos que (el antropólogo) observa y a partir de los cuales y de sus interrelaciones en una sociedad particular abstrae la estructura social, las relaciones, las instituciones, etc., de dicha sociedad.
} 
Como se mencionó con anterioridad, la ley de Paisaje Protegido No 14.126 establece que al año de sancionarse su decreto de reglamentación, publicado el 8 de Octubre de 2010, las canteras afectadas por la medida legal, quienes no presentaron los proyectos de reconversión, debían dejar de funcionar negándoseles la posibilidad de explotar por 1 año más. La Dirección de Minería interpretó que según los tiempos legales el plazo para el cierre definitivo de las canteras era el 16 de Octubre de 2011 teniendo en consideración el artículo 2 del Código Civil, donde se establece que toda ley que no tiene un plazo previsto para entrar en vigencia comienza a regir a los 8 días de la publicación en el Boletín Oficial.

Ante la cercanía de la fecha de cese definitivo de la actividad minera y el rechazo de las medidas cautelares presentadas por los empresarios canteriles por considerar inconstitucional la medida legal ya que la regulación de la actividad minera en la Argentina, según el Código de Minería ${ }^{9}$, corresponde al Estado nacional, se convocó desde la Confederación General del Trabajo (CGT) a un paro general en la plaza central de la ciudad en defensa de los trabajadores de la minería.

El anunció del paro y el temor a sus efectos generó que se llevara a cabo una reunión en la ciudad de La Plata -en la oficina de la Dirección de Minería- entre el municipio, la provincia y la Asociación Obrera Minera Argentina (AOMA) para tratar el tema de la continuidad laboral de los trabajadores de las canteras. Desde AOMA Tandil se hizo hincapié en la incertidumbre de los trabajadores, quienes a pocos días de la fecha prevista desconocían sus destinos. Sumado a lo anterior, se criticaba la eliminación del artículo 16 de la ley que preveía el traslado de la actividad minera por fuera de la poligonal. La reunión generó repercusiones al interior de la ciudadanía; desde el Estado municipal se manifestó públicamente en los medios de comunicación local la ratificación de la ejecución de la medida legal, desatando el paro previsto por el sector minero.

De este modo, los actores que marcharon hacia el municipio fueron los empresarios canteristas, los trabajadores mineros y los transportistas, quienes instalaron sus camiones y acoplados en doble y hasta triple fila en las calles principales que rodean la plaza central y el palacio municipal, como así también dispusieron una carpa y una gran producción de

\footnotetext{
${ }^{9}$ A modo general, rige los derechos, obligaciones y procedimientos respecto a la adquisición, explotación y aprovechamiento de los recursos minerales, por este motivo se constituye en la ley marco en lo que respecta a la regulación minera. A partir del código de minería se derivan diversas leyes que caracterizan la evolución reciente de esta actividad en la Argentina.
} 
pancartas y banderas que daban cuenta de sus reclamos. El Secretario General de AOMA Tandil expresó al respecto:

(...) Lo que pasa es que acá hay una decisión política del intendente Lunghi de no permitir la actividad en otros lugares. (...) Lo que pedimos es que se dejen de jugar a la politiquería ${ }^{10}$, tanto el gobernador Scioli como el intendente municipal. Acá hay gente y puestos de trabajo que tenemos que cubrir (...) Si el Intendente tiene la decisión política de no habilitar ninguna cantera, que se haga responsable de los conflictos sociales que hay en Tandil.

(Portal digital La voz de Tandil, 28/9/2011)

$* * *$
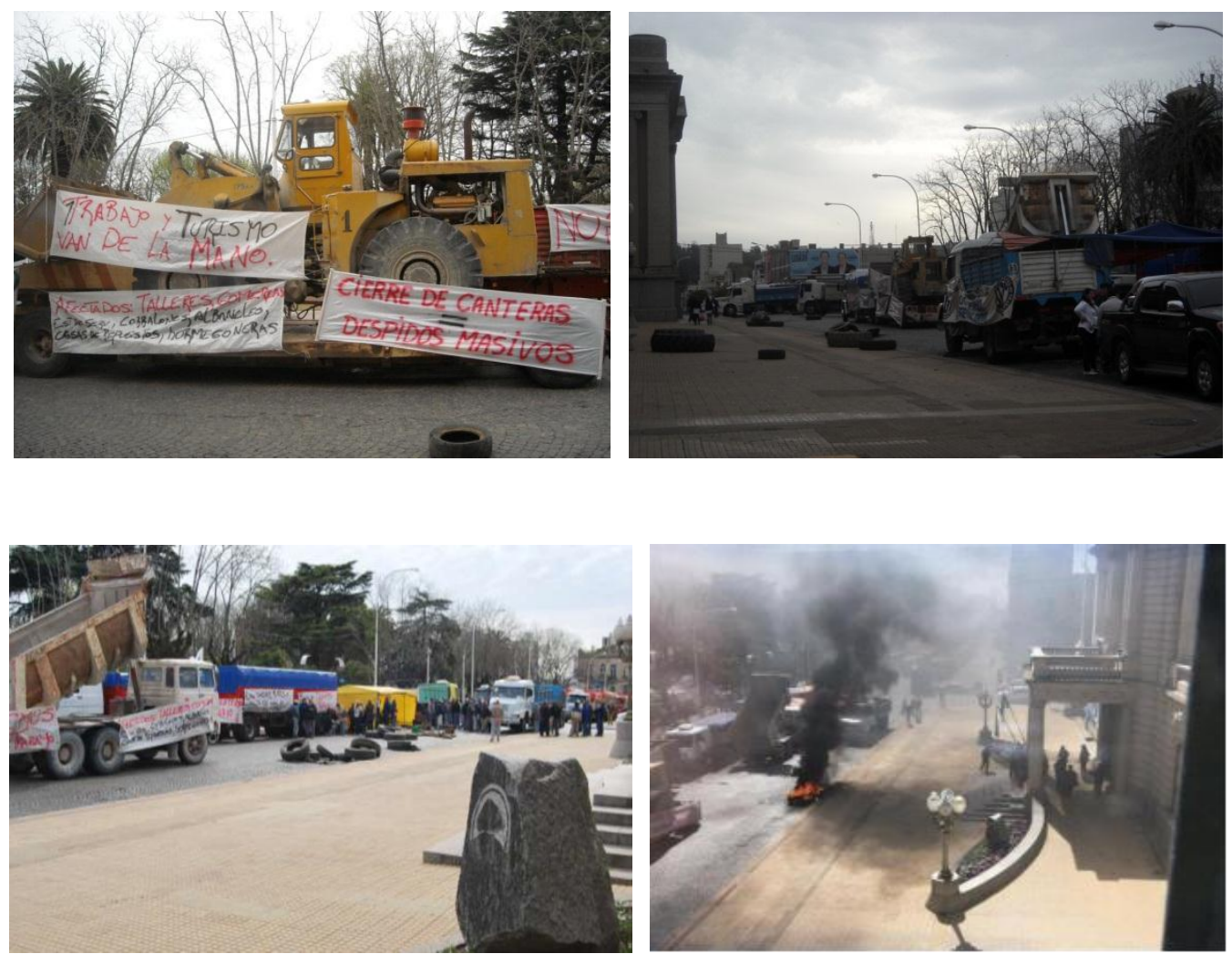

$* * *$

${ }^{10}$ Término despectivo para referirse al ejercicio del poder. 
Los reclamos esgrimidos por los actores movilizados en el ámbito público, quienes a través de un petitorio reclamaban por un lado, la derogación de la ley 14.126 y, por otro, que se produzca el traslado de las canteras por fuera de la poligonal, fueron rechazados por el municipio quien manifestó "la ley no se negocia, se cumple""ll. Asimismo, el aumento de la conflictividad social y la persistencia de los reclamos del sector minero propiciaron la adhesión de diversos sectores de la sociedad local al "estricto cumplimiento de la ley 14.126 que declara Paisaje Protegido a las sierras de Tandil dentro de la Poligonal" lo cual se manifestó en los medios de comunicación local y en la elaboración de solicitadas que empapelaron diversos puntos de la ciudad.

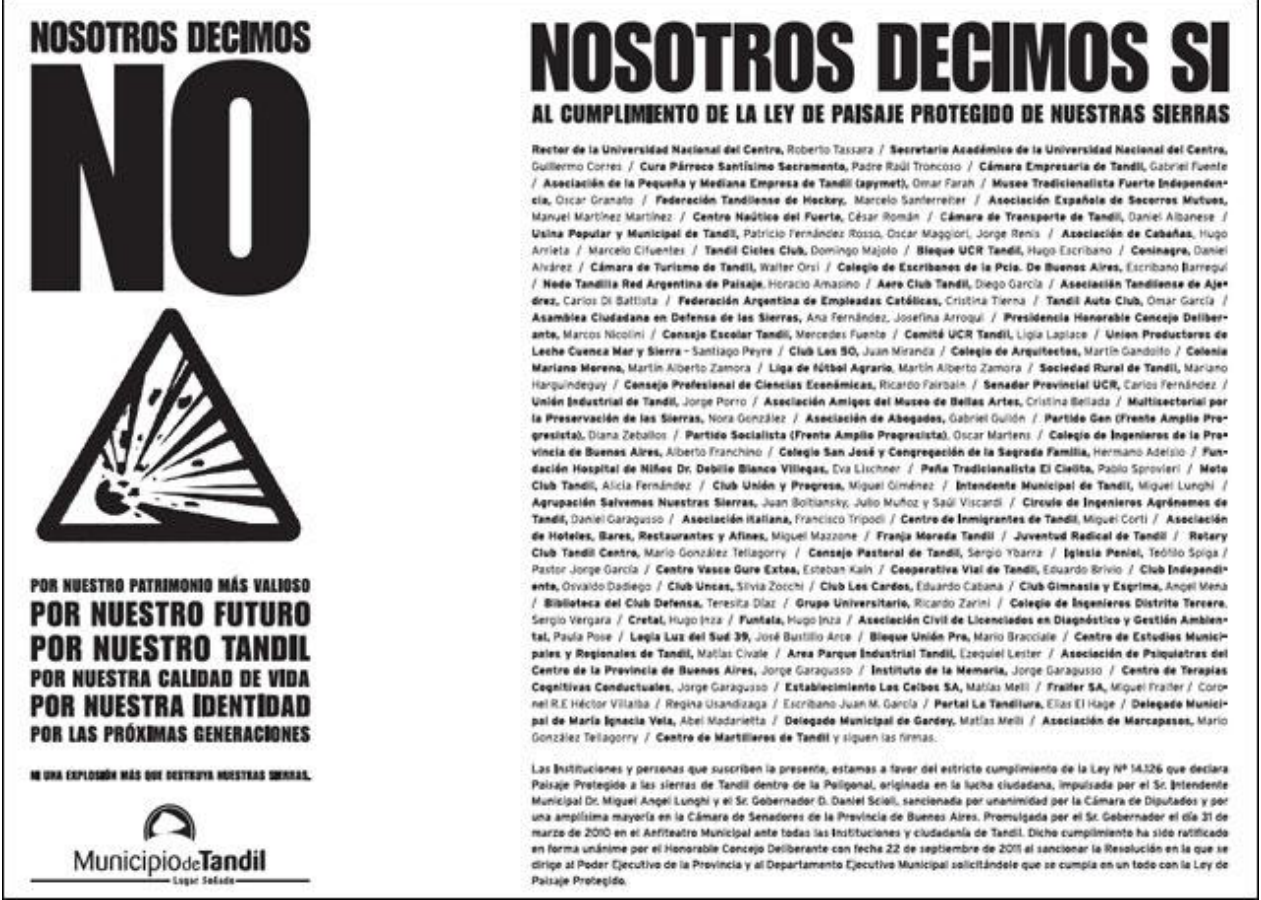

\footnotetext{
${ }^{11}$ Portal digital La voz de Tandil, 02/10/2011.
} 
Ante los sucesos ocurridos el intendente Lunghi agradeció las expresiones públicas de apoyo al estricto cumplimiento de la ley, como así también el apoyo brindado por el gobernador de la provincia de Buenos Aires a la reglamentación de la misma.

(...) llamo a la paz social, al diálogo y a la búsqueda de acuerdos siempre dentro del marco de la Ley y cumpliendo a rajatabla lo que la Ley de paisaje protegido establece. Acá está en juego el patrimonio más valioso que tenemos, que son nuestras sierras, está en juego el futuro, el de las próximas generaciones, nuestra identidad y nuestro modo de vida.

(Portal digital La voz de Tandil, 30/09/2001)

Después de transcurridos varios días de paro, del apoyo masivo de la ciudadanía a favor de la ley, y de una firme decisión municipal y provincial de ejecutarla, los actores en cuestión decidieron entrevistarse con el gobierno municipal el cual abordo de manera diferencial sus reclamos. Al mismo tiempo, el municipio presentó una denuncia penal ante la justicia por impedimento de la circulación y de la prestación de los servicios públicos, ya que la protesta afectaba el acceso a dos escuelas y a una clínica médica ubicada en cercanías al palacio municipal.

Posteriormente, el domingo 2 de Octubre una agrupación ambientalista, la Asamblea Ciudadana en Defensa de las Sierras, convocó a la ciudadanía a participar de una concentración "verde" en el Parque Independencia con motivo del festejo del Día de la Preservación de las Sierras, el cual fue propuesto hace más 10 años y reconocido oficialmente en el marco de este conflicto por el Concejo Deliberante a partir de la Ordenanza 12445. El evento convocó a más de 500 personas entre ellas, integrantes de agrupaciones ambientalistas, autoridades del Ejecutivo y Legislativo municipal (específicamente el intendente Lunghi, el jefe de gabinete y representantes del Consejo Deliberante), organizaciones, partidos locales varios y vecinos. Al respecto miembros de la Asamblea manifestaban:

Pensamos mucho qué teníamos que decir. Lo que queremos destacar es la continuidad de esta lucha. Sería injusto resumirla sólo a este momento. Llegamos acá porque esto tiene una historia y seguramente quedaba muchísimo para hacer. Este es apenas un hito en el camino. Por eso, sobre la cuestión puntual del conflicto que está viviendo en este momento la ciudad, queremos decir ante todo que nuestra posición es bien clara: estamos pidiendo y apoyando el cumplimiento estricto de la Ley. La Ley no se negocia, la Ley no se cambia, la Ley es para cumplirla (...) En ese sentido, creemos que la solución se debe buscar dentro de la Ley, aplicando la Ley, y creemos que esta es la solución más pertinente. Se ha dicho por ahí que pueden duplicar la cantidad de 
extracción en el resto de las canteras, pero como ustedes saben, nosotros vamos a decir hoy lo mismo que dijimos y decimos siempre: todas las sierras de Tandil son importantes y, por lo tanto, no queremos que se deje de romper en unas para que se rompa más en otras. La solución tiene que pasar por otra cosa, y en este caso creemos que hacer cumplir lo que corresponde y que no haya sobrecarga en los camiones, resolvería el tema puntual que se está planteando. Y sobre el resto, lo único que hay acá para decir es que la Ley es y está para cumplirse.

(Portal digital La Voz de Tandil, 02/10/2011)

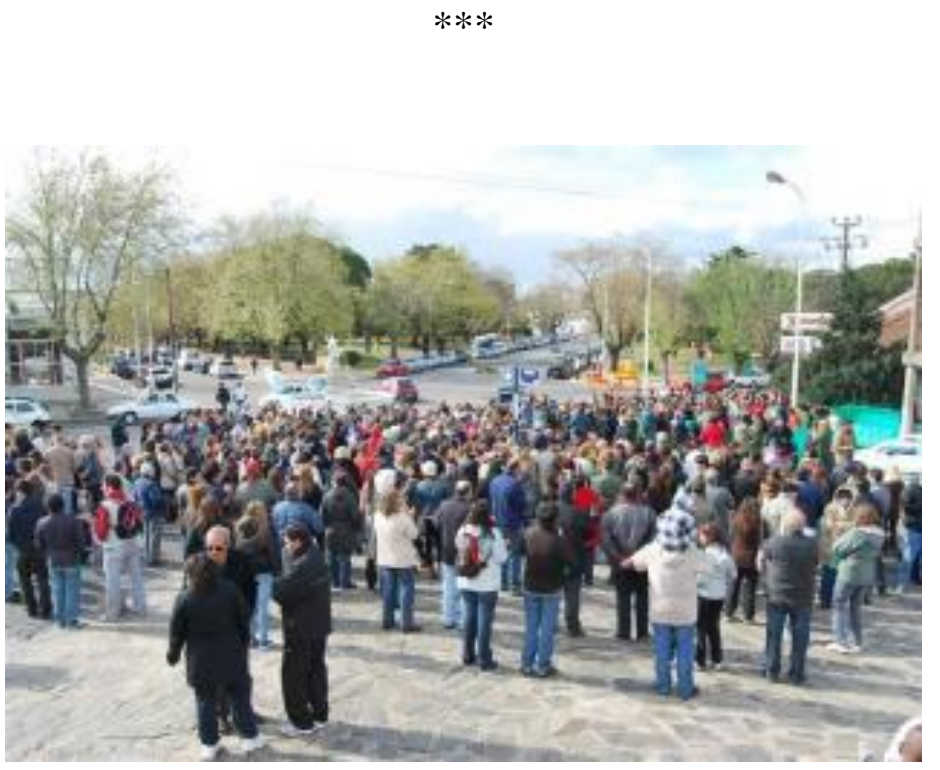

La tensión generada en la sociedad tandilense a partir de la defensa de la ley, fue cobrando mayor grado de violencia y de efervescencia social. En este sentido, el intendente realizó públicamente duras críticas hacia el sector patronal:

Me estoy moviendo solo, vengan a la Plaza, algo, no para que peleen sino para que aplaudan. Estoy lleno de humo hasta el culo ${ }^{12}$, si querés te lo digo (...) acá nadie quiere cumplir ningún tipo de ley. Todo el mundo hace lo que quiere, transportan las toneladas que quieren, hacen recargas por todos lados (...) La política no fracasó, la política larga una ley y la gente quiere hacer lo que quiere. Acá no estamos los políticos solos, estamos toda la ciudadanía, estamos peleando por un recurso natural (...) No quiero enfrentamientos entre hermanos, pero pido que me acompañen a que se cumplan la ley. Si quieren seguir dialogando seguimos dialogando, pero hace un año y medio de esto, no

\footnotetext{
${ }^{12}$ La expresión hace referencia a la quema de gomas que realizaron los manifestantes en frente al palacio municipal.
} 
es una cosa que salió ayer. Los empresarios creyeron que no iba a pasar nada, que iba a seguir todo igual (...) habría que sacar la bandera argentina y poner una banana, somos un país bananero, como vamos a bloquear la plaza principal contra una ley. Es terrible.

(Portal digital La voz de Tandil, 5/10/2011)

Asimismo, la justicia hizo lugar a la denuncia del municipio y a los recursos de amparo presentados por diferentes instituciones locales ordenando el desbloqueo de las calles principales del centro de Tandil. Esta situación redobló el reclamo de los actores movilizados, quienes no sólo bloquearon los accesos de las canteras locales sino también los de la ciudad vecina de Olavarría a los fines de impedir el transporte de granito.

De este modo, todo parecía indicar que hasta el día 16 de Octubre, día estipulado para el cierre de las canteras, el paro seguiría siendo parte del paisaje urbano. Sin embargo, después de 10 días de paro, de una disputa interna en la sociedad que llevó a un apoyo masivo de la ley de Paisaje Protegido, de una firme decisión del Estado municipal y provincial para cumplir con lo reglamentado, y del desgaste de los manifestantes, se aceptaron las condiciones que desde un principio los distintos poderes habían propuesto. Esto era, en lo que respecta a los transportistas evaluar el caso de cada empresa de transporte, cuán grave era su situación a partir del cierre de las canteras con las que trabajaban y, desde allí, algún salvataje -vía subsidio- como con cualquier empresa en crisis o una posible garantía de stock en las canteras que seguirían funcionando. Por otra parte, a los trabajadores mineros se les reitero que estaban amparados por diversos artículos de la ley, y a los propietarios de las canteras no les quedó otra opción que acatar la medida legal. Finalmente el 21 de Diciembre de 2011 se dispuso el cese definitivo de las canteras ubicadas en la poligonal.

\section{Impresiones, dudas y cautela en el trabajo de campo}

El abordaje de los conflictos socioambientales resulta una tarea sumamente compleja ya que se deben identificar los distintos actores sociales y los recursos naturales en pugna, desvelar la dinámica interna, dar cuenta de las estrategias e intereses de los grupos sociales, analizar los discursos y prácticas, y las relaciones implícitas de poder que conforman la arena de disputa (Little, 2006; Leite Lopes, 2006). En lo que respecta al caso de estudio, la información recolectada provino principalmente del trabajo de campo desarrollado con tres grandes grupos de actores sociales delimitados por sus lógicas e 
intereses diferentes: grupos de la sociedad civil (agrupaciones ambientalistas, vecinos pertenecientes a determinados barrios, representantes del "saber experto" y prensa local); actores y protagonistas del campo de la política municipal, provincial y nacional; y grupos con intereses económicos en juego (representantes del sector inmobiliario y del sector minero).

En el presente apartado se darán cuenta de las dificultades, dudas e impresiones existentes en la realización del trabajo etnográfico con uno de los grupos que conforma la problemática de investigación, el denominado "sector minero" compuesto por propietarios canteriles, trabajadores mineros y gremialistas locales. Asimismo, se reflexionará sobre la toma de imágenes fotográficas en el marco de una protesta pública como un intento de plasmar la disputa por la preservación/explotación de las sierras que enfrentan determinados actores colectivos en una arena con pluralidad de significados y prácticas que tienen una construcción socio-histórica.

Resulta preciso comenzar por mencionar que la sanción y ejecución de la Ley de Paisaje Protegido generó que el sector minero adoptara una posición de cautela, negándose a realizar entrevistas y declaraciones. En este contexto, establecí como estrategia acercarme, en una primera instancia, al secretario general de AOMA para que me interiorizara respecto a la actividad minera de la ciudad de Tandil y me sirviera de nexo con las canteras locales. De este modo, gracias a la intervención del gremialista minero pude tener acceso a la cantera Carba, paradójicamente la que mayores controversias genera desde la década del '70 en la sociedad tandilense producto de sus incumplimientos en materia de regulación socioambiental y laboral. La misma es una empresa tradicional de la ciudad- con más de cien años de historia en la explotación del granito-, propietaria de 4036 hectáreas, incluyendo el cerro Las Ánimas y el paseo turístico de la Cascada, y se localiza dentro del área de la poligonal.

Al encuentro con el gerente general de la cantera concurrí con un familiar puesto que la misma se encuentra alejada de la ciudad. Una vez que ingresamos en la calle Carlos Moreno (calle en la cual se ubica la cantera Carba y El Naranjo) íbamos contemplando el paisaje serrano, empero cuando nos acercábamos al destino se podía observar con mayor nitidez la metodología extractivista minera y sus efectos en el paisaje (cráteres y cavas) lo que generó la indignación de mi acompañante. 
Mira como rompen las sierras, hacía un montón que no venía...quieren disimular con árboles lo que hacen...que terrible como esta esto... saca la cinta verde ${ }^{13}$ del espejo retrovisor porque estos de las canteras son terribles, no vaya a ser cosa que se enojen porque estamos a favor de preservar las sierras y nos saquen del lugar.

(Familiar; trabajador metalúrgico; 45 años de edad)

Una vez en la oficina, tuve que esperar la llegada del gerente general lo que me permitió observar con detenimiento el lugar, visualizando en una de las paredes un almanaque en donde cada dibujo hacía referencia a un empleado de la cantera. Cuando llegó el entrevistado me hizo atravesar un taller en donde se encontraban trabajando cinco hombres, los cuales me miraron fijamente y se rieron, situación que me hizo sentir incómoda puesto que se estaba debatiendo mi presencia en el lugar. En el fondo del taller había una escalera que daban a un salón; allí nos dirigimos.

Durante la entrevista, si bien se permitió la toma de diversas fotografías las cuales daban cuenta del modo de funcionamiento de la cantera y sus impactos ambientales en el paisaje serrano, no todas las preguntas fueron respondidas por el gerente y se prohibió la grabación de la conversación por motivos legales, es decir, para que no circulara información de la empresa que pudiera perjudicar sus reclamos en contra de la ejecución de la Ley de Paisaje Protegido. Esta situación permite dar cuenta que la utilización de las técnicas etnográficas se debe adaptar a las posibilidades reales de acceso a los actores en situación y al lugar y contexto donde se desarrolla el trabajo de campo.

Cuando finalizó la entrevista, me detuve en la entrada del reciento porque quería obtener una fotografía de dos carteles allí presentes, uno decía "propiedad privada" y el otro "fin del camino encantado". En el camino a la cantera Carba se puede observar un perfil de las sierras poco antropizado y una exuberante vegetación. En este sentido, el cartel "fin del camino encantado", permite reflexionar respecto a un cambio en el paisaje producto de que se comienzan a vislumbrar los vestigios que la actividad minera genera en las sierras.

\footnotetext{
${ }^{13}$ Símbolo de la lucha por la preservación de las sierras.
} 

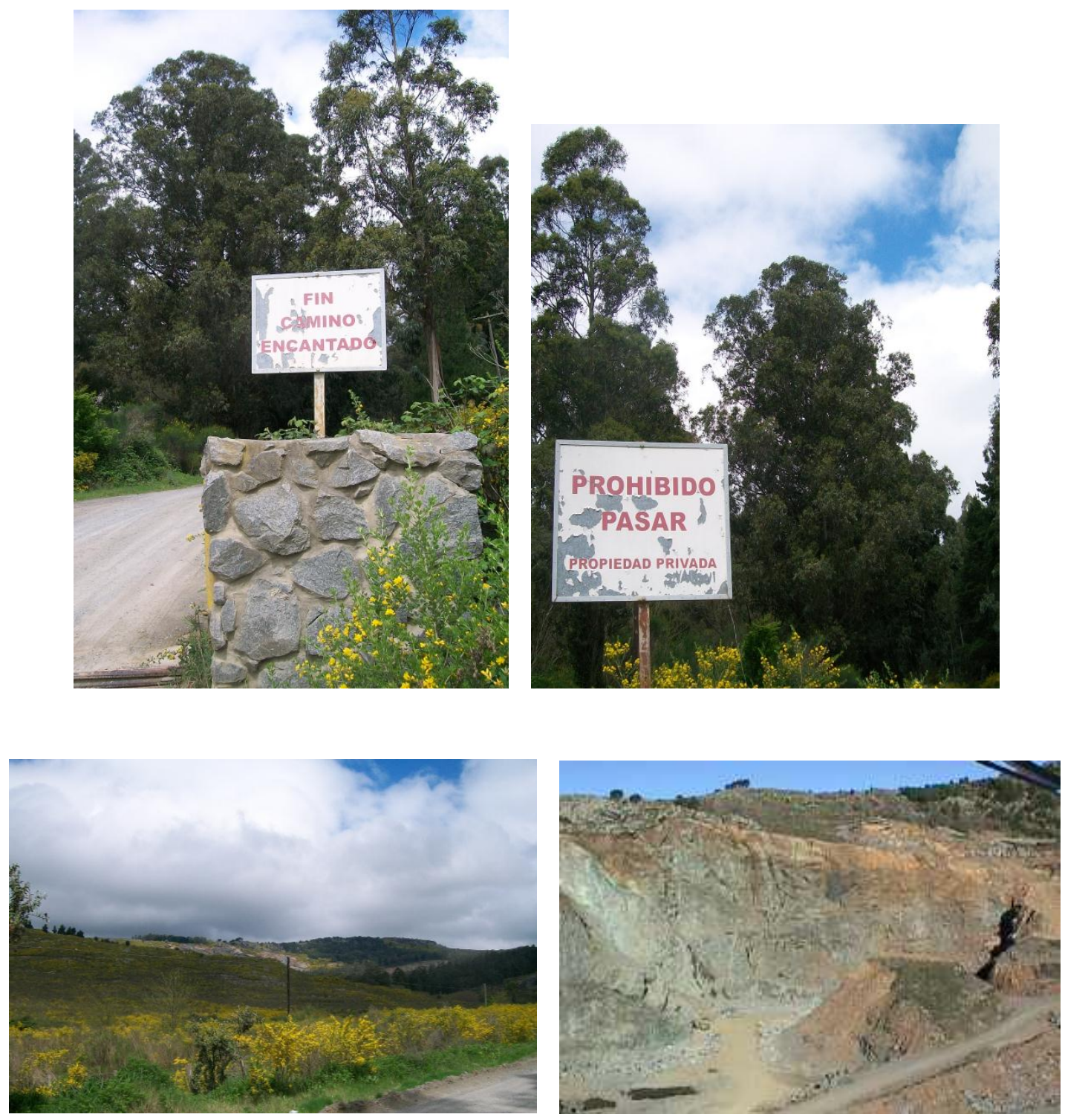

Mientras tomaba las imágenes, pasaron tres camiones cargados con granito y sus conductores se quedaron mirándome inquisitivamente, disminuyendo la velocidad de los vehículos, ante esa situación me dispuse a retirarme. Cuando se está en la zona de canteras se tiene la sensación constante de estar irrumpiendo en propiedad privada. Sumado a ello, la vigencia del debate minero en la sociedad tandilense influye en las prácticas y discursos 
que se adoptan en la investigación a los fines de evitar situaciones de confrontación directa con los actores.

Posteriormente a este encuentro, se produjo uno de los episodios más ricos etnográficamente para registrar los diferentes discursos de los actores que componen el "sector minero". Como se mencionó con anterioridad, el cese definitivo de la actividad minera dentro de la poligonal, establecido por el decreto de reglamentación de la Ley de Paisaje Protegido $\mathrm{N}^{\mathrm{o}}$ 14.126, generó que los empresarios canteristas, los trabajadores mineros y los transportistas se resistieran a la medida y contendieran con el gobierno municipal en un espacio público de la ciudad de Tandil. Estos actores instalaron por varios días sus camiones y acoplados en las calles principales que rodean la plaza central y el palacio municipal, como así también dispusieron una carpa y una gran producción de banderas que daban cuenta de sus reclamos.

Desde los inicios de la protesta social los medios de comunicación cubrieron los sucesos vinculados a la ejecución de la Ley de Paisaje Protegido, primer antecedente provincial en materia de regulación minera. La protesta se constituyó en un tema de interés general no sólo porque se desarrolló en un espacio público significacional para la ciudadanía (Harvey,1877; Hall,1990; Silva,1992; Lynch,1966), siendo posible visibilizar la totalidad de los actores que componen el sector minero ${ }^{14}$, sino también porque permitió que diversos actores sociales debatieron a través de sus discursos y prácticas los modos de gestionar la problemática minera, al mismo tiempo que conflictuaron los proyectos de ciudad en pugna, siendo actualizada por un lado, la pregunta identitaria de ¿qué ciudad queremos? y, por otro, la disputa de "para quién de la ciudad y sus sectores""15 y el "derecho a la ciudad" $" 16$.

\footnotetext{
${ }^{14}$ En la ciudad de Tandil existe la representación social de que la mayor parte del empresariado minero resulta foráneo. En este sentido la protesta posibilitó identificar a los dueños de las canteras afectadas por la ley, quienes son oriundos de la ciudad.

${ }^{15}$ Gravano, 2005.

${ }^{16}$ El término surgió en los años 70 ante el planteamiento del filósofo y sociólogo francés Henri Lefebvre, el cual consideró el impacto negativo sufrido por las ciudades en los países de economía capitalista, construyendo una propuesta política que parte de la ciudad para reivindicar la posibilidad de que los sujetos, y no el capital, volvieran a ser dueños de la misma y se logrará establecer el "buen vivir" para todos. Este concepto es retomado por Borja quien manifiesta "(...)Ya no es suficiente plantear el derecho a la vivienda, a la educación o al trabajo: estos derechos se hacen más complejos y se expresan como el derecho a la ciudad(...)” (Borja, 2003).
} 
Con el transcurrir de los días el paisaje urbano seguía siendo un microcentro sitiado por los camiones, generando el repudio de diversos sectores de la sociedad respecto a las modalidades de protesta de los manifestantes ya que obstaculizaban el libre tránsito de las personas, al mismo tiempo que exigían la ejecución de la Ley de Paisaje Protegido.

El incremento del debate público en torno a la explotación/preservación del sistema serrano, los pedidos de participación desde el gobierno Municipal en apoyo al cumplimiento de la ley, y el aumento de adhesiones y firmas de instituciones locales y vecinos a favor de la preservación de las sierras hicieron que me dispusiera a concurrir a la plaza central con el objetivo de tomar fotografías de la protesta, de las múltiples voces que allí se entrecruzaban, puesto que se constituía en un "resurgir" del conflicto por el uso, gestión y ocupación del sistema serrano.

Si bien en la plaza se vivía un clima de tensión entre los manifestantes y las personas que circulaban, me dispuse a tomar fotografías porque la protesta se desarrollaba en un contexto de registro público estando implícita la posibilidad de que fuera fotografiada o filmada por parte de diversos medios audiovisuales, más aún, a partir de las acciones de los manifestantes (la disposición de banderas, los bloqueos de calles, la quema de gomas, etc.) se quería visibilizar el conflicto y lograr un cambio en la gestión de la problemática minera. Empero, el querer acercarme al sector minero, esta vez desde lo fotográfico, me generó nuevamente una serie de inquietudes y temores vinculados al desprecio de los actores, a su negativa de tomar fotografías y, finalmente, a generar una situación conflictiva que implicara el retirarme del lugar sin el material deseado. Sumado a ello, "el ser mujer" y "joven" son aspectos problematizados por los actores, generando limitaciones en el desarrollo de la investigación en lo que respecta por un lado, al acceso de ciertos lugares e información y, por otro, a la relación que se establece con el/los entrevistado/s.

Sumado a ello, algunos manifestantes habían agredido a periodistas ante el temor de ser identificados fotográficamente, como así también a ciudadanos y miembros de las agrupaciones ambientalistas quienes expresaban repudio a los reiterados incumplimientos legales del sector y a su lugar histórico de poder en la arena de la política ambiental.

En ese contexto, me dispuse a tomar fotografías. En un primer momento comencé por capturar imágenes generales de la plaza, de las personas que circulaban y de los 
edificios históricos; a medida que me sentía más cómoda en la realización del trabajo de campo me dispuse a tomar imágenes de los camiones que bloqueaban las calles principales del centro y las banderas que daban cuenta de sus pedidos, situación que confirmó mis mayores temores. Un grupo de manifestantes se me acercó, conformando un semicírculo, y comenzaron a indagar respecto a los contextos de uso que tendrían las fotografías, la justificación de la utilización de la cámara de fotos como herramienta complementaria para el desarrollo de una investigación no sirvió para lograr una interacción consentida. Los manifestantes dieron cuenta de la "sospecha de espionaje", vinculándome una posible dependencia estatal como así también la defensa de intereses contrarios a sus reclamos. La situación de vulnerabilidad a la que me vi expuesta generó que me retirara del lugar a los fines de evitar posibles agresiones. De este modo, no se logro una interacción consentida con los actores sociales lo que dificultó la continuidad del trabajo etnográfico.

\section{Reflexiones finales}

A partir de un estudio de caso en una ciudad media de la provincia de Buenos Aires, se intentó mostrar las dificultades que se presentaron en el desarrollo del trabajo etnográfico durante la intensificación del conflicto socioambiental en torno a la explotación/preservación del sistema serrano de Tandilia.

La práctica de la etnografía implica procesos de negociación de la interacción con los actores sociales a los fines de lograr su consentimiento durante el transcurso del trabajo de campo. Asimismo, cuando la investigación se desarrolla en el marco de una protesta social los actores reclaman que se proteja sus identidades tanto en la construcción textual como en la producción de imágenes. Las mismas cobran sentido a partir de evidenciar y comprender las estructuras sociales, las relaciones de poder, los imaginarios urbanos y los intereses económicos que subyacen en ellas. Es a partir de las herramientas teóricas y metodológicas que ofrecen las ciencias sociales que se puede revelar la dimensión antropológica de lo fotografiado.

Si bien en la ciudad de Tandil la protesta que llevaron adelante los empresarios canteriles, trabajadores mineros y transportistas en contra de la ejecución de la Ley de Paisaje Protegido se desarrolló en un espacio público, el contexto de registro no posibilitó lograr el consentimiento de los manifestantes para la toma de imágenes. Por este motivo, la 
decisión ética/metodológica de no utilizar a la fotografía en tanto instrumento de representación de la realidad se vinculó con las relaciones concretas que se establecieron con los actores sociales investigados quienes reclamaban por un lado, que se proteja sus identidades y, por otro, poder seleccionar las fotografías a los fines de decidir "así me muestro", "así me escondo".

De este modo, el presente artículo ambicionó poner en relieve cómo la conflictividad existente en torno a la explotación minera permite debatir el lugar diferencial del recurso natural sierras en los diferentes proyectos de ciudad en pugna, al mismo tiempo que visualiza el papel central de la etnografía en la disputa "por un lugar en la ciudad".

\section{Referencias}

ABCHOY. Disponible en: http://www.abchoy.com.ar/

ADOLFO, Estalella y ELISENDA, Ardèvol. "Ética de campo: hacia una ética situada para la investigación etnográfica de internet”. In: Forum Qualitative Social Research, v. 8, n.3, Art. 2. Berlin: Freie Universität Berlin, 2007.

ARDÈVOL, Elisenda. La búsqueda de una mirada. Barcelona: Editorial UOC, 2006.

ARDÈVOL, Elisenda. La mirada antropológica o la antropología de la mirada: De la representación audiovisual de las culturas a la investigación etnográfica con una cámara de video. 1994. Tesis doctoral - UAB, Barcelona, 1994.

ARDÈVOL, Elisenda. "Por una antropología de la mirada: etnografía, representación y construcción de datos audiovisuales". In: Revista de Dialectologia y Tradiciones Populares. Madrid: ILLA/ CSIC, 1998.

BALANDIER, Georges. El poder en escenas. De la representación del poder al poder de la representación. Barcelona: Ediciones Paidós, 1994.

BOGGI, Silvia y GALVÁN, Nora. "Ni chicha ni limonada. Apuntes reflexivos acerca de las nociones de ciudad media y ciudad intermedia". In: Ponencia presentada al IX Congreso Argentino de Antropología Social, 2008, Posadas, Misiones, 5 al 8 de agosto.

BORJA, Jordi. La ciudad conquistada. Madrid: Alianza editorial, 2003.

EDWARDS, Elizabeth. Anthropology and photography, 1860-1920. London: Yale

University Press, 1992.

EDWARDS, Elizabeth. "Las prácticas sociales como una teoría de la fotografía". En: VICENTE, Pedro (ed.). Instantáneas de la teoría de la fotografía. Tarragona: Arola, 2009. p.101-112.

EL ECO DE TANDIL. Disponible en: http://www.eleco.com.ar/

GAZZOTI, Luciana. "Dilemas de da práctica profesional: cuando la ética y la moral devienen en problemas antropológicos". En: Revista Runa, n.28. Buenos Aires: UBA,2008. p. 29-42. 
GIRADO, Agustina. "Resistencias y conflictos socioambientales en Tandil. Un estudio de caso". En: Revista Sociedad y Equidad, n.4. Santiago de Chile: Universidad de Chile, 2012. p. 22-43.

GLUCKMAN, Max. "Análisis de una situación social en Zululandia moderna". En: Bricolage. Revista de estudiantes de antropología social, n.1. Ciudad de México: UAM, 2003. p. 34-49.

GRASSI, Estela. Políticas y problemas sociales en la sociedad neoliberal. La otra década infame (II). Buenos Aires: Espacio Editorial, 2004.

GRAVANO, Ariel (Comp.). Imaginarios sociales de la ciudad media. Emblemas, fragmentaciones y otredades urbanas. Estudios de Antropología Urbana. Tandil: Centro Editor de la UNICEN, 2005.

GUBER, Rosana. El salvaje metropolitano. Buenos Aires: Editorial Legasa S.A., 1990.

HALL, Edward. "El espacio habla". En: El Lenguaje Silencios. México: Alianza, 1990.

HAMMERSLEY, Martyn y ATKINSON, Paul. Etnografía. Métodos de Investigación. Buenos Aires: Ediciones Paidós, 1995.

HARVEY, Daniel. Urbanismo y desigualdad social. Madrid: Siglo XXI, 1977.

LA VOZ DE TANDIL. Disponible en: http://www.lavozdetandil.com.ar/

LEY DE PAISAJE PROTEGIDO N 14.126.

LEITE LOPES, José Sérgio. "Sobre processos de ‘ambientalização' dos conflitos e sobre dilemas da participação". En: Horizontes Antropológicos. Antroplogia e meio ambiente, v.12, n.25. Porto Alegre: UFRGS, 2006. p. 31-64.

LITTLE, Paul Elliot. Ecología Política como etnografia: um guia teórico e metodológico. En: Horizontes Antropológicos. Antropologia e meio ambiente, v.12, n.25. Porto Alegre: UFRGS, 2006. p. 85-103.

LEZAMA, Alejandro. "La Imagen Audiovisual en Antropología: Oportunidades y desafíos". En: Revista Chilena de Antropología Visual, n.1. Santiago: CEAVI, 2001. p. 5965.

LYNCH, Kevin. La imagen de la ciudad. Buenos Aires: Infinito, 1966.

NOÉ ECHEVARRÍA, Marcela. "Ciudadanía y Políticas Públicas". En: CORREA, Enrique y ECHEVARRÍA, Marcela Noé (Comp.). Nociones de una Ciudadanía que crece. Chile: FLACSO, 1998. p. 38-60.

PLAN DE DESARROLLO TERRITORIAL.

ROCHA, Ana Luiza Carvalho y ECKERT, Cornelia. "Ética e Imagem: Um Percurso". En: Revista Iluminuras, v.5, n.11. Porto Alegre: BIEV/ UFRGS, 2004. p. 1-13.

ROCKWELL, Elsie. La experiencia etnográfica. Historia y cultura en los procesos educativos. Buenos Aires: Paidós, 2009.

SILVA, Ana. "Imágenes e Imaginarios Urbanos en la "Ciudad de las Sierras"”. En: Revista Iluminuras, v.11, n.26. Porto Alegre: BIEV/ UFRGS, 2010. p. 1-21.

SILVA, Armando. Imaginarios urbanos. Bogotá y Sao Paulo: cultura y comunicación urbana en América latina. Bogotá: Tercer mundo editores, 1992.

Recebido em: $31 / 10 / 2012$

Aprovado em: 20/12/2012 